Research article

\title{
A note on precocious pollen germination in Woodfordia fruticosa (L.) Kurz.
}

\section{Kanak Sahai*, Krishna Kumar Rawat and Dayanidhi Gupta}

CSIR-National Botanical Research Institute, Rana Pratap Marg, Lucknow-226001, India

*Corresponding Author: sahaikanak@rediffmail.com

[Accepted: 22 November 2016]

\begin{abstract}
The unusual phenomenon of pollen germination prior to their release from anthers was studied in detail in different samples of flowers collected from different geographical regions of India viz. Eastern Himalayan region (Teesta valley near Darjeeling, West Bengal), Western Himalayan region (Yamuna bridge near Mussoorie and Pauri Garhwal district), Gangetic plains (Katerniaghat Wildlife Sanctuary, Uttar Pradesh) and arid region of Rajasthan (Mount Abu). Though pollen germination prior to their release was regularly observed during the study, it varied at different level of anther and stigma and in different geographical regions. Highest i.e. $7.31 \%$ of such type of pollen germination was recorded in the samples of Pauri Garhwal of Western Himalayan region followed by $3.45 \%$ from Mussoorie of the same region when flower was at its initial stage of opening and pistil was short and below the level of anther. This phenomenon of pollen germination was regularly absent in the samples of Eastern Himalayan region.
\end{abstract}

Keywords: Precocious pollen germination - Himalayan - Gangetic plain - Arid region.

[Cite as: Sahai K, Rawat KK \& Gupta D (2016) A note on precocious pollen germination in Woodfordia fruticosa (L.) Kurz. Tropical Plant Research 3(3): 606-610]

\section{INTRODUCTION}

Precocious pollen germination inside the anther loculi are commonly reported to occur in cleistogamous flowers (Maheshwari 1962, Frankel \& Galun 1977, Lord 1979). However, It has also been observed in some chasmogamous flowers by many workers like Trigonella foenum-graecum (Joshi \& Raghuvanshi 1967), Lathyrus sativus (Verma \& Grewal 1971), Bergenia crassifolia (L.) Fritsch, Citrus limon (L.) Burm. Fil, Cucumis melo L. cv. Giant stide (Tezier), Prunus avium L. cv. Mora di Cazzano, (Pacini \& Franchi 1982); Malus pumila, Prunus amygdalus (Koul et al. 1985), Catharanthus roseus (Mishra \& Kumar 2001), Arabidopsis thaliana (Johnson \& McCormick 2001, Xie et al. 2010), Biophytum sensitivum (Sreedevi \& Rekha 2003), Glycine max (Kaur et al. 2005) etc. While working on various samples of Woodfordia fruticosa (L.) Kurz. collected from different parts of the country, the interesting phenomenon of pollen germination inside indehisced anther lobe was observed and investigated further in detail for the present study. Since Woodfordia fruticosa is an important dye yielding (Dymock et al. 1890, Uphof 1959, Das et al. 2007) and medicinally important species (Kuramochi-Motegi et al. 1992, Liu et al. 2004, Chandan et al. 2008), its overexploitation reported it threatened species (Kokkirala et al. 2012) and even now listed as Low risk/Least concerned species (IUCN 1998). A perusal of literature reveals though, multifarious properties of Woodfordia fruticosa were highlighted from time to time, studies on reproductive behavior are almost lacking so far. Woodfordia fruticosa with chasmogamous flowers regularly showed pollen germination inside anther lobes. Hence, this phenomenon not reported so far in this plant species was considered interesting for the present study.

\section{MATERIAL AND METHODS}

Study species

Woodfordia fruticosa (Lythraceae) commonly known as 'Fire flam bush' due to brilliant red flowers is a shrub/small tree. It is endemic to India and also distributed in Bhutan, China, Indonesia, Laos, Madagascar, Myanmar, Nepal, Pakistan, Sri Lanka, Thailand and Tropical Africa (Abbasi et al. 2012, Meena \& Kumar 2015). The plant is known for various medicinal properties including anti-tumor, antioxidant, 
immunomodulatory, antiproliferative, antihyperglycemic, antimicrobial, anti-inflammatory and analgesic, hepatoprotective, cytotoxic, preventive \& curative and anti-ulcer activities (Rani et al. 2015). The flowers have wider use in Ayurvedic formulations like 'arishta' and 'asava' (Kores et al. 1993). Of the 18 aristas, 17 have been found to contain Woodfordia fruticosa (Meena \& Kumar 2015).

Study sites

Flowers and buds of various stages of Woodfordia fruticosa were collected from four different geographical regions of the country viz. Eastern Himalayan (Teesta valley near Darjeeling, West Bengal), Western Himalayan (Yamuna bridge near Mussorie and Pauri Garhwal district), Gangetic plain (Uttar Pradesh: Katerniaghat wildlife sanctuary) and Arid region of Rajasthan (Mount Abu).

\section{Sample preparation and observation}

The randomly collected flowering material from different geographical regions of India was fixed in FAA and later preserved in $70 \%$ alcohol. Flowers and buds of different stages were observed under dissecting microscope for morphological studies. Indehiscent anthers and stigmas of different developmental stages were selected, dissected and examined under microscope. Since stigma was present at the different level of anthers, the pistil was categorized as short (stigma below the anther level), medium (stigma equal to anther level) and long (stigma above the anther level) and the stigma receptivity was tested for each category with Benzedine test (Galen et al. 1985). Pollen grains were extracted from anther lobes corresponding to the entire three pistil category and stained with Alexander's stain (Alexander 1980). Observations were made under stereoscopic zoom microscope to check the pollen viability, sterility as well as their germination inside the anther lobe and photographed with the help of Nikon Eclipse 80i microscope. Percentage of fertile pollen grains and their germination inside anther was assessed by counting the pollen grains in randomly selected microscopic fields. Average score was calculated from 25 such ramdom counts for each sample. For histological observation, samples were dehydrated in tertiary-butyle-alcohol series and infiltrated and embedded in paraffin wax. Thin sections of $10 \mu \mathrm{m}$ were cut through rotary microtome, double stained with Safranine and Fast green and finally mounted onto Canada balsam. Microphotographs were taken with the help of microscopic camera attachment.

\section{RESULTS AND DISCUSSION}

Study species

The plant has simple, opposite, sessile or shortly petiolate, ovate-lanceolate or lanceolate leaves. Flowers are irregular, born in axillary cymes, bright red and bisexual; calyx tubular; petal small; stamen 12; ovary superior with numerous ovule. Fruit membranous capsule; seeds numerous, wedge-shaped, brown and smooth (Jayaweera 1981, Napagoda \& Yakandawala 2008).

Table 1. Pollen status and its perecocious germination along with different developmental stages of stigma in Woodfordia fruticosa of different geographical region. ( $\mathrm{S}=$ Short pistil, $\mathrm{M}=$ Medium pistil, $\mathrm{L}=$ Long pistil)

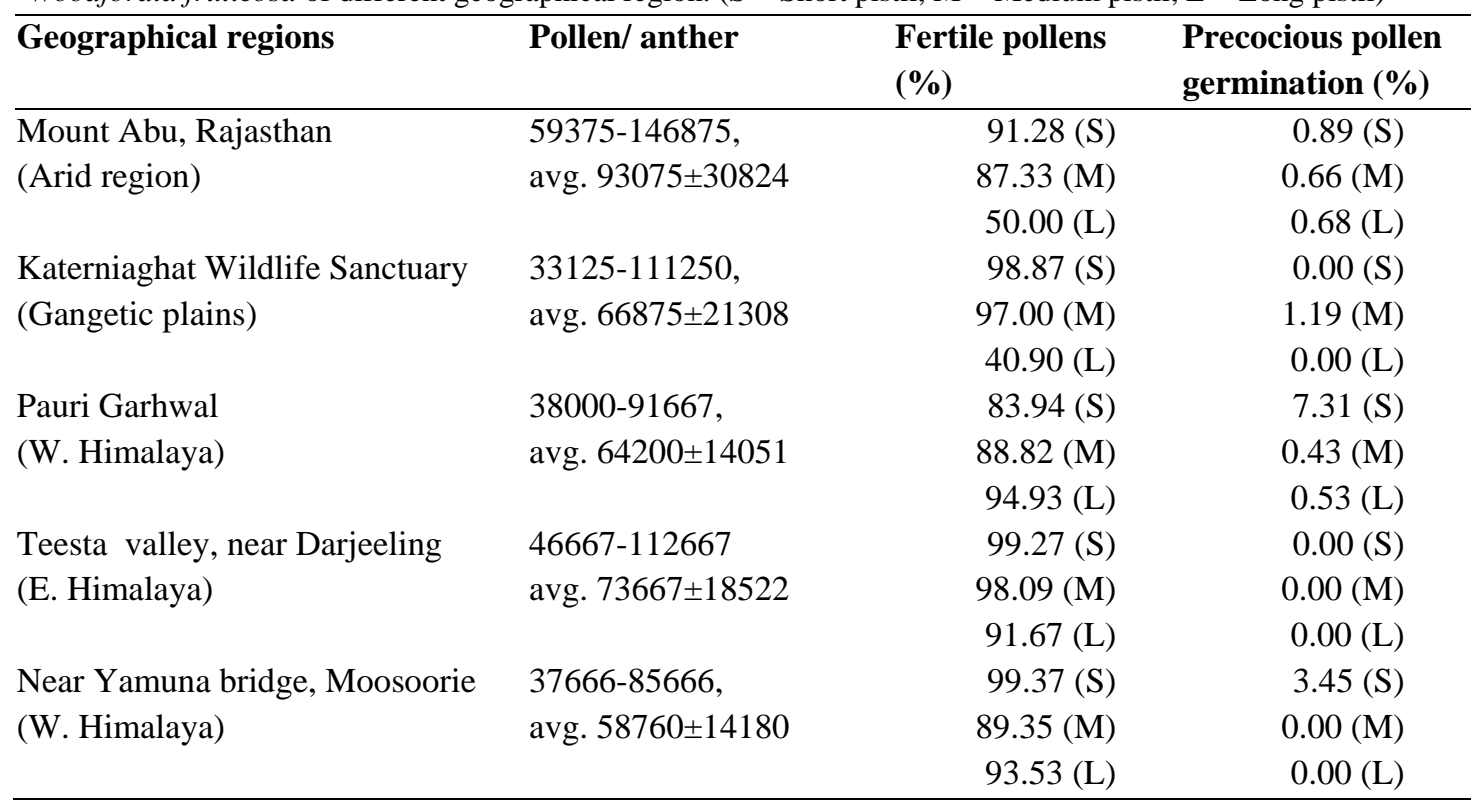



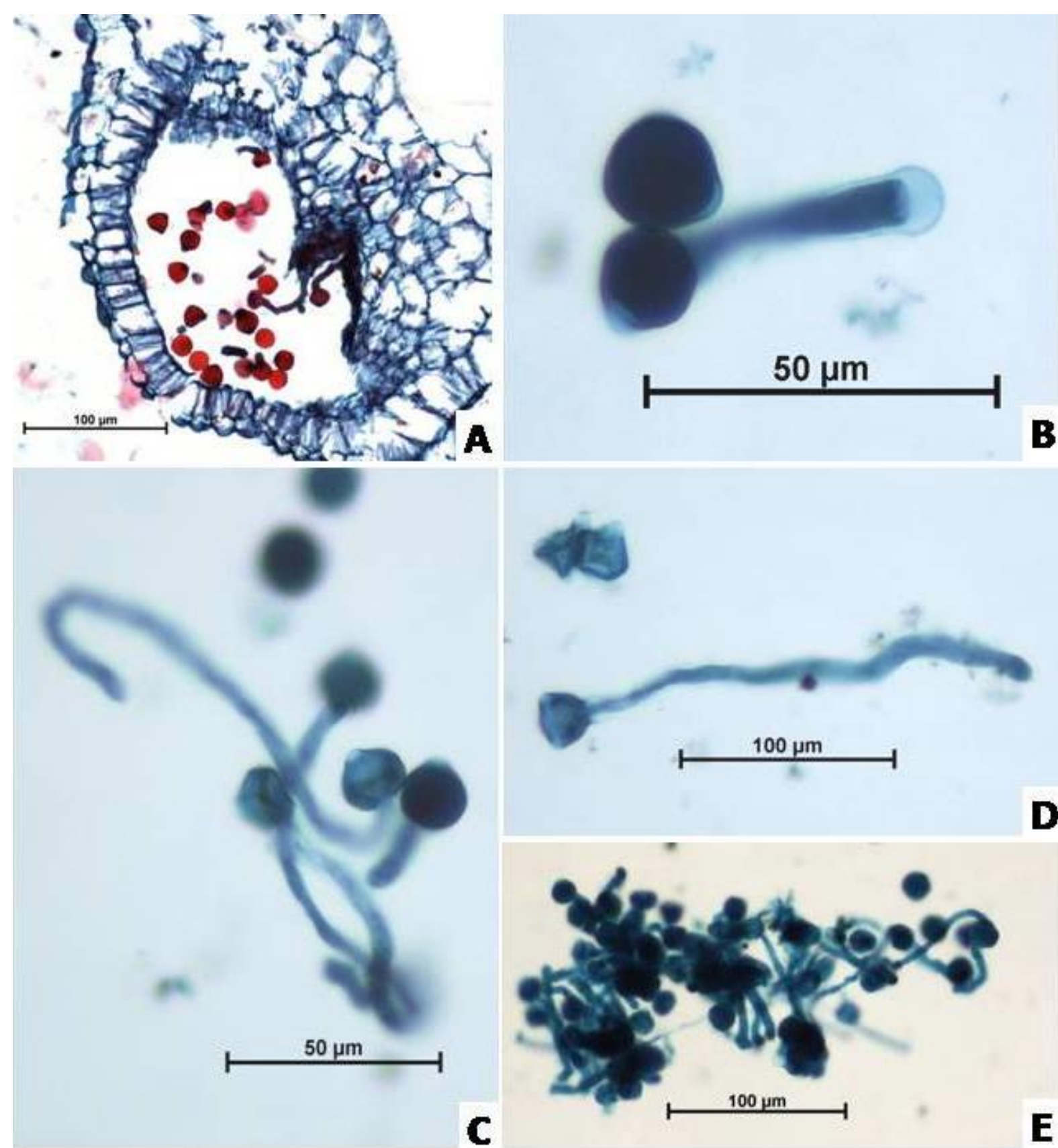

Figure 1. Precocious pollen germination in Woodfordia fruticosa. A, section of anther lobe showing germinated pollen grains; B-D, germinating pollen grains with pollen tubes of varying length; $\mathbf{E}$, germinated pollen grains forming cluster.

Stigma became receptive along the flower opening and the receptivity reached at peak at the level of anthers (medium sized pistil), which gradually decreased when stigma passes the anthers and reached above the anther level (long pistil). However, pollen viability has no concern with the in-situ pollen germination (Table 1). Pollen germination inside anther (Fig. 1A-E) was observed in all the samples of three different eco-geographic regions, viz. western Himalayan and Arid region and Gangetic plain except in the samples of eastern Himalayan region where this phenomenon was absent in spite of repeated visits and random collections (Table 1). Pollen germination prior to their release from anther (precocious pollen germination) greatly varied provenance to provenance. It was highest i.e. $7.31 \%$ in the samples collected from Pauri Garhwal of western Himalayan region followed by 3.45\% from Mussoorie of the same region (Table 1). Interestingly in both the samples, the maximum in-situ germination was recorded at the initial stage of flower opening when pistil was short and below the level of anthers. However, in open flower stage, when pistil reached either at the level of the stamen (medium sized pistil) or above them (long pistil), the pollen germination was poor or even absent in some samples (Table 1). Such phenomenon of pollen germination did not occur at the same rate in all the samples; it varied at different levels of anthers in respect to stigma and in different geographical regions (Table 1). In some www.tropicalplantresearch.com 
cases pollen germination inside the anther was observed in clusters and therefore, eventually released together (Fig. 1E). These pollen clusters may also create obstruction for other pollen to discharge freely at once from anther and thus act as a hindrance to selfing (Verma \& Grewal 1971). On the other hand, as a result of in-situ germination and subsequent obstruction, the pollen will come out slowly and therefore, pollen discharge may lost longer, which may attribute to long lasting chances of selfing as suggested by Kaur et al. (2005) who described in-situ pollen germination in Glycine max as a strategy to facilitate a high degree of selfing. However, Koul et al. (1985) suggested that in-situ pollen germination is probably controlled by genetic factors as they observed the phenomenon in specific varieties of apples growing along with many other varieties in the same environment. According to them such type of pollen germination does not occur year after year which indicates that certain environmental condition is necessary for the expression of particular gene or genes responsible for precocious pollen germination in particular plant species. They speculated the reason of limited number of precocious pollen germination either they do not carry the same potential of germination or not exposed strictly to similar conditions inside the anthers. Similar observations were made by Mishra \& Kumar (2001) in Catharanthus roseus and found this mechanism as genetically controlled. Dhar et al. (2002) co-related precocious pollen germination with high relative humidity and high soil moisture. This fact is evident from our observation as the maximum pollen germination inside the anther lobe was observed in Western Himalayan samples where high humid conditions were usual. Interestingly, contrary to them, the samples collected from dry arid area (Rajasthan) regularly revealed precocious pollen germination at all the stages of pistil, though the percentage was not very high (Table 1 ).

During the normal case of pollen germination the moisture content of pollen grains as well as of the microsporangium is reduced as the anther ages (Koul et al. 1985). The pollen grains get partially dehydrated and the locular fluid disappears before anthesis to promote anther opening and pollen grain dispersal. Reaching onto the stigma, the pollen grains rehydrate before germination by absorbing the water provided by the receptive stigma (Heslop-Harrison 1979a, 1979b). The extent of dehydration varies plants to plants according to pollination strategies and meterological conditions at anthesis (Baranas \& Rajki 1976). Partially dehydrated pollen grains could easily germinate in-situ, where probably the locules remain wet. Precocious pollen germination with partly dehydrated anther has been observed in seagrass Thalassodendron ciliatum (Ducker et al. 1978). The wet loculus and absence or delay of pollen dehydration, was speculated to trigger pollen germination inside anthers by Pacini \& Franci (1982). However, in our opinion pre dispersal pollen maturity is more responsible for precocious pollen germination. Since all the pollen grains inside the anther lobe did not take part in germination (Fig. 1A), only mature pollen grains that got moisture might be able to germinate. Though, it is very difficult to speculate whether the pre- germinated pollen grains takes part in self or cross pollination/fertilization, once the pre-germinated pollen or pollen cluster reaches to the receptive stigma of same flower, it can enhance the possibility of self-pollination to some extent due to already grown pollen tubes. Cross pollination due to precocious pollen germination cannot be successful as the dispersal of germinated pollen grains and their landing on to the stigma surface in a healthy condition cannot be expected because they can be damaged mechanically by exposure to dry air. However, this mechanism of precocious pollen germination needs further analysis to find out its real causes and significance.

\section{ACKNOWLEDGEMENTS}

The authors are grateful to the Director, CSIR-National Botanical Research Institute, Lucknow for kindly providing the necessary facilities. The study was conducted with the financial support from Council of Scientific and Industrial Research (CSIR), New Delhi under project head OLP-0083.

\section{REFERENCES}

Abbasi AM, Khan MA, Ahmad M \& Zafar M (2012) Medicinal plant biodiversity of lesser Himalaya-Pakistan. Springer, New York, London, 220 p.

Alexander MP (1980) A versatile stain for pollen, fungi, yeast and bacteria. Stain Technology 55: 13-18.

Baranas B \& Rajki E (1976) Storage of maize (Zea mais L.) pollen at $-196^{\circ} \mathrm{C}$ in liquid nitrogen. Euphytica 25: $747-752$.

Chandan BK, Saxena AK, Shukla S, Sharma N, Gupta DK, Singh K, Suri J, Bhadauria M \& Qazi GN (2008) Hepatoprotactive activity of Woodfordia fruticosa Kurz. flowers against carbon tetrachloride induced hepatotoxicity. Journal of Ethnopharmacology 119(2): 218-224.

Das PK, Goswami S, Chinnaiah A, Panda N, Banerjee S, Sahu NPB \& Achari B (2007) Woodfordia fruticosa: Traditional uses and recent findings. Journal of Ethnopharmacology 110: 189-199. 
Dhar R, Sharma N, \& Koul AK (2002) Intra population variation in site of pollen germination and pollination in Trifolium fragiferum L. Phytomorphology 52: 323-330.

Ducker SC, Pettitt SM \& Knox RB (1978) Biology of Australian seagrasses: pollen development and submarine pollination in Amphibolis antarctica and Thalassodendron ciliatum (Cymodoceaceae). Australian Journal of Botany 26: 265-285.

Dymock W, Warden CJH \& Hooper D (1890) Pharmacographia Indica. Education Society's Press, Byculla, Mumbai, 206 p.

Frankel R \& Galun E (1977) Pollination mechanisms, reproduction and plant breeding. Springer Verlag, Berlin, 284 p.

Gale C, Plowright RC \& Thompson JD (1985) Floral biology and regulation of seed set and size in the lily, Clintonia borealis. American Journal of Botany 72(10): 1544-1552.

Heslop-Harrison J (1979a) An interpretation of the hydrodynamics of pollen. American Journal of Botany 66: 737-743.

Heslop-Harrison J (1979b) Aspects of the structure, cytochemistry and germination of the pollen of rye (Secale cereale L.). Annals of Botany 44 (suppl.1): 1-47.

IUCN (1998) CAMP workshop on Medicinal plants, India (January, 1997) 1998. Woodfordia fruticosa. The IUCN Red List of Threatened Species 1998: e.T39058A10160263. Available from: http://dx.doi.org/10.2305/IUCN.UK.1998.RLTS. T39058A10160263.en. (accessed on 02 August, 2016).

Jayaweera DMA (1981) Medicinal plants (indigenous and exotic) used in Ceylon. The National Science Council of Sri Lanka, Colombo.

Johnson SA \& McCormick S (2001) Pollen germinated precociously in the anthers of raring-to-go, an Arabidopsis gametophytic mutant. Plant Physiology 126: 685-695.

Joshi S \& Raghuvanshi SS (1967) B-chromosomes, pollen germination in situ and connected grains in Trigonella foenumgraecum. Phyton 12: 278-282.

Kaur S, Nayyar H, Bhanwra RK \& Kumar S (2005) Precocious germination of pollen grains in anthers of soybean (Glycine $\max ($ L.) Merr.). Soybean Genetics Newsletter 32: 1-10.

Kokkirala VR, Kota S, Yarra R, Bulle M, Aileni M, Gadidasu KK, Teixeira da Silva JA \& Abbagani S (2012) Micropropagation via nodal explants of Woodfordia fruticosa (L.) Kurz. Medicinal and Aromatic Plant Science and Biotechnology 6(1): 50-53.

Kores BH, Vanden Berg AJJ, Abeysekera AM, DeSilva KTD \& Labadie RP (1993) Fermentation in traditional medicine. The impact of Woodfordia fruticosa flowers on the immunomodulatory activity and the alcohol and sugar content of Nimba arishta. Journal of Ethnopharmacolgy 40: 117-125.

Koul AK, Singh A, Singh R \& Wafai BA (1985) Pollen grain germination inside the anthers of two chasmogamous angiosperms: Almond (Prunus amygdalus L. Batsch) and Apple (Malus pumila Mill.). Euphytica 34: 125-128.

Kuramochi-Motegi A, Kuramochi H, Kobayashi F, Ekimota H, Takahashi K, Kadota S, Takamori Y \& Kikuchi T (1992) Woodfruticosin (Woodfordin C), a new inhibitor of DNA topoisomerase II. Experimental antitumor activity. Biochemical Pharmacology 44: 1961-1965.

Liu MJ, Wang Z, Li HX, Wu RC, Liu YZ \& Wu QY (2004) Mitochondrial dysfunction as an early event in the process of apoptosis induced by Woodfordin I in human Leukemia K562 cells. Toxicology and Applied Pharmacology 194: 141-145.

Lord E (1979) The development of cleistogamous and chasmogamous flowers in Lamium aplexicaule (Labiatae); an example of heteroblastic inflorescence development. Botanical Gazette 140: 39-50.

Maheshwari JK (1962) Cleistogamy in angiosperms. In: Maheshwari P, Johri BM \& Vasil IK (eds) Proceedings of the Summer School of Botany. Ministry of Scientific Research and Cultural Affairs, New Delhi, India, pp. 145-155.

Meena V \& Kumar S (2015) Woodfordia fruticosa (L.) Kurz.: A high demand threatened plant with potential medicinal values. Indian Journal of Plant Sciences 4(3): 100-106.

Mishra P \& Kumar S (2001) A monogenic recessive mutant with precocious in situ pollen germination in Catharanthus roseus L. Journal of Medicinal and Aromatic Plant Sciences 23: 277-279.

Napagoda NADR \& Yakandawala K (2008) Woodfordia fruticosa (Lythraceae): A medicinal plant for landscaping. In: Proceedings of $6^{\text {th }}$ Agricultural Research Symposium, 13-14 August 2008. Makandura, Wayamba University of Sri Lanka, pp. 294-298.

Pacini E \& Franchi GG (1982) Germination of pollen inside anthers in some non-cleistogamous species. Caryologia 35: 205-215.

Rani S, Rahman K, Younis M \& Basar SN (2015) Dhawa (Woodfordia fruticosa (L.) Kurz.): A versatile medicinal plant. International Journal of Pharmaceutical Sciences and Drug Research 7(4): 315-320.

Sreedevi P \& Rekha B (2003) Pollen features and germination of Biophytum sensitivum var. sensitivum DC. Phytomorphology 53(2): 157-164.

Uphof JC Th (1959) Dictionary of Economic Plants. H.R. Engelmann (J. Crammer), Weinheim, Germany, 400 p.

Verma SC \& Grewal SS (1971) Precocious germination of pollen in Lathyrus sativus and its significance. Phytomorphology 21: 362-367.

Xie B, Wang X \& Hong Z (2010) Precocious pollen germination in Arabidopsis plants with altered callose deposition during microsporogenesis. Planta 231: 809-823. 